\title{
Suitability and context for brief therapy
}

\author{
GERTRUD MANDER
}

Foundation for Psycho-Therapy and Counselling

\begin{abstract}
The main point of this paper is that a client's suitability for brief or time-limited therapy is determined by various factors, including context. There is still agreement on the validity of Malan's selection criteria, which included 'mild illness, recent onset, high motivation and response to trial interpretation', yet many additional issues have since emerged and need to be considered. For instance, the counsellor's suitability, training and work experience, the counsellor's assessment skills and ability to establish a dynamic focus, the clients' capacity for self-reflection, their ego strength and their response to a trial therapy in the first session. Then there is the importance of the various contexts in which nowadays much brief counselling is offered free to clients, whether in education, at the workplace, in primary healthcare settings or by charitable organizations. This means that issues of money and markets have come to the fore and an initial differential assessment needs to be carried out in order to decide which method or model of therapy is best for the client. Matching the counsellor's personality to the needs and to the pathology of the client, and matching the treatment to the client's developmental stage or life stage crises are other aspects of the work, which determine the issue of suitability. In the end as always there is much that remains unknown about what works for whom and how the client's decision to take up help is made.
\end{abstract}

Keywords: Brief dynamic therapy, selection criteria, suitability, counsellors' training and assessment skills, dynamic focus, money and markets, developmental issues, life stage crises.

I want to start off with a case encountered in the context of an employment assistance programme. The client, a 38-year-old woman who worked in human resources for a city law firm, came because she wanted to explore why she was unable to settle down with a man. None of her relationships had been long-term and she was worried about remaining single. There was something plastic about her, a professional persona that was impeccable. Her history revealed that her mother had developed MS when the client was 14 years of age and had died some years ago, unable to speak in the last

Correspondence: Gertrud Mander, 24 Chalcot Crescent, London NW1 8YD. E-mail: g.mander@virgin.net 
stages of her disease. The client had been a keen rower and had aspired to participate in the Olympic Games, but was not chosen for 2004. In the first session she broke down and cried when she talked about her mother's death. This made her go back to the service provider to ask for more sessions, indicating that she had been deeply affected when she shared her story. Was she suitable for brief work? Two issues made the counsellor hesitate: the unfinished mourning for the mother who had been ailing for so many years, and the fact that the client was working in human resources, advising clients at their workplace. Was she asking for more, i.e. long-term work? How could she get what she needed? Serially, intermittently, or in an open-ended form?

The suitability of clients for brief therapy is no longer as hotly discussed as it was in the 1980s when many forms of short-term, time-limited and brief therapy first came on the scene. These have become accepted, some of them are funded by the government and they are available in a plurality and diversity of contexts to different client populations: in education, in primary healthcare, in workplace settings and all kinds of specialized services for bereavement, alcohol, drugs and sexual abuse.

Suitability criteria for brief therapy were first established by David Malan (1979) and were divided into 'radical' and 'conservative'. He listed the conservative view as: 'Only acute illnesses in basically well-adjusted personalities are suitable. Brief methods should be used only when longterm methods are not available', and the radical view as 'good results can often be achieved in severe, long-standing illnesses and brief methods may in certain cases be more suitable than long-term methods. Quite farreaching changes are often possible'.

Malan listed his selection criteria as 'mild illness, recent onset, and good motivation', in other words, as Freud had said, 'the patient should be ill enough to seek help, but not too ill to make use of it', i.e. patients who arrived at 'propitious moments in their lives, had Oedipal problems, some satisfactory relationships, and demonstrated good contact and response to trial interpretation'. Moreover, it seemed important that 'the patient's life problem can be clearly defined and offers a clear-cut theme or focus for therapy' (Malan, 1979, p. 243).

Malan's contemporary Sifneos treated only patients with Oedipal problems and excluded pre-Oedipal conditions, contrasting anxietyprovoking treatment with anxiety-suppressive therapy, and tailoring contract lengths to the patients' presenting problems and psychopathology. Another one of the early practitioners, Habib Davanloo, maintained that 'the patient's response to a period of trial therapy was the best indicator of their suitability for the treatment', which he considered an 'unlocking of the unconscious' (Davanloo, 2000). These pioneers based themselves on Edward Glover's (1955) classical list of decreasing treatability - hysteria, conversion symptoms, compulsive neurosis, character disturbance, 
perversions, addictions, lack of impulse control, psychosis; and they guided the first generations of brief therapists through the controversial discussions in the profession about brief and time-limited work, until the wide public availability of different brief versions and the advent of employment assistance programmes shifted the focus dramatically to issues of money and markets, contract length, technique and modest goals.

There are now many contexts that offer funded brief therapy to people from all age groups and walks of life. The main question is still how to separate clients who are suitable from those who are not. For instance: what should one offer the 40-year-old train-driver and father of four children by two marriages, who asked for counselling at a community counselling service called 'Open Door' because of his intermittent depression, and began his assessment session by telling the counsellor that his mother had died when he was 12 years of age and that he wanted to start training in psychology? Should he be given 12 sessions to help him come off his medication, focus on his childhood loss and his mid-life crisis, or should he be invited to enter open-ended long-term work to explore everything that was troubling him? How much time should be offered to the 77 -year-old woman who was busy running committees in her community and having extensive treatment for bowel cancer, who was complaining of her husband's lack of interest in sex with her and had lost touch with her three grown-up children years ago? Would one decide to give her openended counselling and listen to her tales of woe or offer her a dozen sessions in which to help her reconnect with her children before her almost certain imminent death?

These two cases from my supervision practice appealed to the brief therapist in me and I encouraged the counsellors to focus on loss and mourning in both cases and thus to enable the clients to deal with a lifestage crisis rather than address the full complexities of their life stories and emotional problems. I was reminded of the primary importance of context in brief work, of the variable client populations who need treatment, and of the diverse styles and therapeutic attitudes of available counsellors that determine a client's suitability for brief therapy. Many contexts offer very brief and time-limited contracts to specific clients - at the workplace, in schools and universities, at GP practices or charitable services. Most of these clients are newcomers to counselling, their knowledge of counselling is scant and they usually expect instant help in a crisis. Usually the decision whether they are seen briefly is determined by the counsellor's judgement and experience, or by the availability of resources, while the client's motivation, ability to self-reflect, to tell their life story and to establish a relationship may be of secondary consideration.

Many contexts are now specifically geared to offer short-term contracts, and what clients get depends on how skilfully they are assessed in their first session and on the work experience that the counsellor has. I believe that 
almost everybody can be seen briefly, if only for a thorough assessment, but I also believe that brief therapy is best when it is a first therapeutic experience. When it works, and when the client feels helped significantly, it can lead to more and longer or to a different kind of therapy at another time in their lives. If it doesn't work, if nothing helpful happens, and there is no 'meeting of minds' (Stern, 2004), it may have been a waste of both the participants' time, but perhaps not much will be lost, except when the client has experienced the therapy as traumatic and felt abandoned when it ended. What is most important therefore is that the context is well set up, is containing for both the client and for the counsellor, and that the parting of the ways is handled appropriately. Then there may be no more than disappointment, the client has had a taster and did not take to it, the counsellor has had a try and failed. The lack of a good outcome may however seriously effect clients who have experienced previous failures in their lives and think of themselves as failures. Then the skilled therapist needs to contain the damage by suggesting and negotiating referral to a more appropriate service and attempt to get the client seen for a longer time, or suggest another alternative, in which the client can feel understood and held.

Of course, some clients may never try again. Failed attempts may give our work a bad name, but therapy is not a panacea. What matters in the long run is that there are enough practitioners who are trained to do their work well and responsibly and who are able to fit the method to the recipient. Many clients can be helped first time round by a stint of brief therapy, when they have understood something better, made some changes and had a good experience of being listened to. It can encourage them to try again later on, when they need more or a different kind of help. Much depends on the match of personalities and especially on the quality of the assessment. This needs to be carefully done on the basis of personal experience of how much to open up in somebody, of what is on offer and, ultimately, of faith in the process. Then it can enable the client to acquire a more reflective attitude towards their problems and their life story, to use the following sessions creatively and to repair some deficit or to regain their balance. Much depends on the counsellor's training. There is still a tendency to assume that doing brief therapy is easier than long-term work. A common mistake is to think that beginners start with short-term work and that with increasing experience they learn to keep their clients longer and to go deeper. In fact they often lose their clients in the early stages, because they mistake flight into health for success, when they are unable to establish a working alliance which ensures the client's co-operation. Beginners often have their first counselling experience in placements which offer brief contracts, and they may find it difficult to help these clients focus on problems that can be worked with briefly and dynamically. They may launch anxiously into the work without assessing from the life story whether 
clients are capable of establishing trusting rapport, whether they can reflect on themselves, are articulate enough to communicate their difficulties and can make meaningful links in their life story that pinpoint the problems they are presenting with.

Beginners may also be anxious about getting it right, about giving clients enough, about understanding what troubles them or where they are developmentally, and they may be unable to practice the necessary 'selective attention and selective neglect' that is needed to find a focus in the clinical material. They may also find it difficult to set modest goals and to contain the masses of information a client may flood them with. This means that they have to be thoroughly trained and selected for their suitability to do brief work as they need to get hold of where the client is psychologically and developmentally, how well they respond to the active dialogue of the brief method, and how much self-scrutiny they are capable of. Moreover, they need to have had some experience of therapy themselves, both brief and long-term, both as practitioners and in their own personal therapy so that they know what the client may be experiencing during the work.

Choosing clients suitable for brief therapy thus requires a shrewd eye for the clients' most troubling emotional problems, for their ability to establish and to use a relationship, and for the psychological-mindedness that facilitates a therapeutic dialogue. The Canadian analyst Habib Davanloo, one of the grand old masters of Intensive Short-term Psychotherapy, believed that clients' suitability was established by subjecting them to the 'vital ingredients of the treatment that was to follow', that is, to a 'trial therapy', in the first session. This would test their ego strength, their availability for using interpretation, their defensive structure and their motivation for change. All the indications or contraindications should be judged in context. There are also dimensions of personality style, of matching expectations and of developmental profiles, which are significant, when suitability is decided. Davanloo's selection criteria, like Glover's treatability conditions, would seem to apply to any candidate for psychotherapy of whatever length, as is a sufficient level of articulacy, of intelligence and of a capacity for involvement in a dialogue.

\section{Settings}

It is also rewarding to consider the treatment contexts and the candidates' age group, when establishing their suitability. Much brief therapy, for instance, is offered to young adults in educational settings, where the clients' most frequent pressing issue is the age-specific separation from their parents and from their home, which tests their maturity, autonomy levels, and sense of identity. In other words, they inhabit a transitional space between a restrictive or contained environment and the risk-demanding 
open territory of young adulthood. The counsellor working in this setting with adolescents will have to focus on these issues in order to establish how far individual clients have succeeded in the developmental tasks of achieving independence, of starting to individuate and to form an identity, whether they have the strength and resources to cope with the necessary parting from their parents, and why they are faltering in making career choices and becoming functioning adults.

The same separation-individuation dynamics will probably be repeated in the brief therapy relationship and much will depend on how the therapist handles the parallel processes between task achievement and therapy termination. Brief therapy may generally be the treatment of choice for young people because of the developmental position they have reached and need to reach, and a regressive open-ended treatment would run counter to their developmental task of achieving independence from family and parents.

Separation issues also operate in bereavement counselling where the clients' suitability for brief counselling depends on their capacity to mourn, to let go of persistent ambivalent attachments and to resolve unfinished business with the dead. This can be facilitated and strengthened by an emphasis on the time-limit and by working with the count-down method towards an agreed ending that becomes an example for the stages and closure of the necessary mourning.

\section{Primary care contexts}

In the GP practice the counsellor will be dealing with a varied group of clients, with high rates of depressive, anxious and somatizing clients whose capacity to face difficult emotions is often impaired and habitually channelled into bodily symptoms. A willingness to face defensive and deep-seated strategies of avoidance determines the patient's suitability for brief work, and once again the choice might depend on the patient's ego strength, their self-awareness and motivation for change, as 'they are going to exchange their chronic suffering for the acute but passing pains of insight which take over from the personality problems presented with initially' (Coltart, 1996, p. 149). Another difficulty in this setting is the method of referral from doctor to counsellor, which requires the patient's active participation in a therapeutic dialogue rather than medication, and this depends on the doctor's knowledge of and belief in the efficacy of counselling. In this context a good collaboration between the doctor and the counsellor is of vital importance, as the client's transference is to the practice, and is therefore split between doctor and counsellor, with the doctor assuming an ongoing paternal role and performing a gatekeeper function, which will always influence the counsellor's working alliance with the patient and their assessment. There are also issues of funding, as GP 
practices are accountable to their mental health trust which is paying the counsellors, and the doctors have the first say on the selection of patients for therapeutic treatment.

Most surgeries nowadays employ practice counsellors who do brief work. Some of these practice CBT (Cognitive Behavioural Therapy) and offer patients structured time-limited treatments which many people consider less strenuous than psychodynamic counselling and more cost-effective. Patients go to their doctors with all kinds of practical, emotional or somatic complaints and it is important that they are engaged fruitfully in a tentative exploration of emotional conflict that could help them to understand what they really need. They might be encouraged to have a series of short-term sessions spaced out over time with the approval of the doctor. This work could constitute the beginning of a change towards treatability in a psychodynamic manner, and then lead on to referral out to another service. Much of the diagnostic work is hypothetical, may be based on trial and error and may be the assessment of chronic conditions that might take some time to improve or for which new solutions may not be found. There is always the need to beware of false optimism.

Suitability for successful short-term work in the primary care sector is an elusive subject and most brief work in the medical context happens because it is an available rather than an optimal solution to patients' conditions. The heart-sink and worried-well patients who people GP surgeries may not be 'cured' by the primary care counsellor, but research indicates that the patients' symptoms can change, that they can find emotional relief and often appreciate this resource as an offer of help, as a good experience of support and of being listened to, and as an incentive to go on hoping. In the end, probably only a multi-disciplinary approach will shift many of these conditions over time (Wiener \& Sher, 1998).

\section{Employee assistance programmes}

Another context in which client suitability for time-limited work is a complex issue is the fast-expanding world of counselling at the workplace and of employment assistance programmes, where many therapists nowadays earn part or most of their livelihood. The allocation of EAP clients is in the hands of the service provider who refers clients to the counsellors who are on their books, usually on the basis of their geographical proximity. In the initial assessment session the client's suitability to be treated is established on the basis of the presenting problem(s), and of the psychodynamic focus that can be formulated by the counsellor together with the client after taking a personal and medical history. All this depends on the rapport and understanding achieved between the two participants. On beginning treatment an agreement is necessary to contract for the number of sessions allowed by the service provider, which becomes the 
moment of choice and of skilful negotiation between client and therapist. Who decides what happens now? If the counsellor has misgivings about the client's suitability, will this alone decide the issue? Does the client have an independent say and can s/he demand they go ahead together? Will the counsellor need to go into more detail for a decision if they disagree? Can the counsellor use persuasion to achieve a decision or does the client's behaviour decide? Is the outcome always a compromise?

Clearly clients have a decisive part in establishing the suitability of working together, depending on the strength of their motivation and on their initiative of making a choice for the therapist, for whom they may decide unconsciously in their vulnerable state. This complicates matters considerably, as their motives might be mixed. Are they taking a risk? Do they not care whom they get? Is there already an unconscious transference developing that reaches back to their primary relationships.

\section{The client's part in the choice}

The question of suitability is never a one-sided affair decided by the therapist. Even when an agreement is reached at the end of the first session to go ahead together, this does not always happen. Clients sometimes change their minds and decide not to return, perhaps because they are ambivalent, they may not have much hope that counselling is suitable for them, or they just vote anxiously with their feet. This is not an option the therapist has, but the client's decision prevails in this situation. Yet the therapist may have a change of mind on discovering that the client proves to be more disturbed or needy than at first appeared to be the case. This may then require a joint decision to find another option. When the client returns, the sessions have to go ahead and this means that the client has decided the issue of suitability. Then the therapist is duty-bound to enter into a process that has started and it is decisive how he or she conducts the work to lead to a satisfactory outcome, which may well be a referral into long-term work, when the client shows signs of regression or dissociation which will need more containing ongoing work.

Thus the decision-making is never simple and the client can be more active in having a say than is expected by the counsellor. Daniel Stern (2004) describes how in any kind of therapy there is a momentum of 'moving along' that overrides clear-cut decisions of suitability. In this 'intersubjective matrix' it is uncertain who is in control, the process simply takes over and needs to be trusted. In some respects, therefore, suitability can only really be known with hindsight when the counselling has worked, when the focus has been well formulated, has provided insight into the client's problems, leads to a resolution, allows for mutative interpretations, creates a surprise or a new understanding, in other words, when a process has been set in motion in the client's mind 
that has therapeutic consequences. In the end this means that the choice of suitability is always hypothetical, even though it can turn out later to have been very accurate.

In the context of EAP work it seems that the client who gets allocated through the service provider often does not know at first what they are getting themselves into and they usually need guidance about whether they have come to the right place. As the counsellor is guaranteed to be paid, not by the client but by a third party who gets paid by the client's employer, the first interview is a sounding out of what is on offer, what the client's expectations are, where the client is emotionally and developmentally, whether they can tell a plausible life story, engage in a dialogue, what their emotional baggage is, and what in particular has brought them in. This establishes the parameters, but it is not always a clear assessment for suitability.

The important fact is that EAP clients are usually self-referring, which means that they have a reason for asking to see a counsellor which is something of very recent vintage that makes the question 'Why now?' so important. Another fact is that the counselling is free for the client, and that the experience is a brief encounter, which is easier to embark on than the uncertainty of an open-ended commitment. The counsellor's first task is to make the encounter meaningful and to focus on a problem that can be tackled creatively rather than embarking on a lengthy exploration that might become uncontainable. What matters is that there is instant rapport that can lead to a moment of change, however small. Clients who are not sure what they want will often not take up the offer of more sessions, but they may have been affected by having been listened to in an unusually attentive way which may have made them curious about something they did not know about themselves. The briefness of the encounter matters less than the quality of it.

The EAP client often comes with issues relating directly to their workplace, to their colleagues and their bosses, which means that the counsellor has to be sensitive to the organizational dynamics and needs to connect these with deeper personal and relational dimensions that may not be immediately obvious. It is worth finding out why the client is working with a specific organization, e.g. one client who worked with Amnesty International came from a background of political instability and she found her trips to the Congo very traumatic until she discovered parallels with her own background, which explained why this was so and the knowledge of this dynamic enabled her eventually to change her job.

There are often sensitivities about confidentiality issues, the client may have been sent by their organization because of persistent absenteeism, or it may turn out that he/she is a drug or alcohol abuser, which may require more time and a more specialized treatment than is on offer. The counsellor will have to negotiate with the service provider for more sessions, perhaps for a referral out, or for a form of intermittent brief therapy which is spaced 
out over the length of time it would take to make a significant difference to the presenting problem. In many cases, counselling can turn into a whole package of treatments that involve other approaches on top of or instead of talking. Not everybody, whether client or counsellor, is suited for this complex task nor capable of negotiating with the organization and/or the service provider.

EAPs vary in their generosity and methodology - many of them nowadays allow the counsellor more than one period of brief work with their clients, or the clients are permitted to re-contract with their counsellors on a private basis for ongoing therapy. Private practice is less suitable for brief therapy because of scheduling difficulties, but experienced practitioners are able to establish flourishing consultancies for corporate referrers which rely on them for the management of their work force. This requires good financial and administrative skills.

In all the contexts I have mentioned it is essential on first meeting to establish the degree of pathology and the type of defences a client uses. Equally important is the client's motivation and the client's willingness to engage. When this amounts to trust, there can be instant rapport, when there is resistance and rigid defensiveness, this will mean ambivalence or high levels of anxiety and the therapy will take a long time to get under way. The accuracy of initial assessment is the prerequisite for achieving a psychodynamic formulation, establishing a working alliance and attempting a trial therapy in the first session (Mace, 1995).

As for the issue of 'working through' after the brief therapy finishes, this is debatable, as it requires an ability of corrective self-scrutiny which not every client is capable of or will acquire in the course of the brief therapy. If they haven't, there could be an erosion of what was done during the therapy or a return to the status quo. Much depends on the outcome - whether the client has resolved an important issue, has reached the depressive position, has been able to internalize the therapist and has learnt some lessons from the therapy experience.

Finding new solutions to old problems could be said to sum up the goal of brief therapy succinctly, together with the modest aim of 'making a difference' or, in the words of Gregory Bateson, 'to make a difference that makes the difference'. There should also have been some emotional re-enactment as rational insight alone is insufficient and needs to be backed up by a transformational experience. There may also be a difference of outcome for the two participants themselves: what the client might consider satisfactory may be far from the therapist's expectations, and to establish who is right is well nigh impossible. Indeed, evaluation of outcome on the point of ending therapy can be different from what is seen to have been achieved or not achieved a few weeks, months or years later. In the end there is the possibility of more therapy at a later stage - for which the brief therapy may have been an introduction, a rehearsal, and a strengthening of motivation. 
It is vital that the brief therapy, although a brief encounter, amounts to a therapeutic experience that becomes internalized and enables an ongoing process of 'working through' after a good enough ending. The memory of having been helped significantly will then become an incentive of seeking help again if necessary, with the same or with another therapist, perhaps even with some alternative form of therapy, not necessarily of the 'talking' variety, for instance with CBT or with one of the newer models such as EMDR or 'energy therapy', which are conquering the market of brief therapy.

I often compare brief therapy with the short story, in contrast to the novel: it is an episode, instead of a chronicle, a sharply focused limited time, instead of the diversity of a whole world, or in the words of William Blake, the experience of 'seeing the world in a grain of sand, and eternity in an hour'. It opens windows, enables a transformative experience, sets something in motion that becomes healing and life-altering and may usher in the depressive position, which means giving up the pleasure principle for the reality principle, enables reparation, mourning and the internalization of the counsellor.

It might be interesting to finish with a case of trauma debriefing in brief therapy, with a client whose partner disappeared in the recent tsunami. The young couple had been living together for a while in a relationship that had not yet stabilized and the man had gone off to Thailand on his own to a town which they had once visited together. There was no contact after the tsunami had struck this particular part of Thailand and the client was in despair about what to do.

The first reaction had been action, i.e. go to the town where the partner had gone, but then she heard from her partner's sister that he could not be traced there. Then she realized that she was angry with him and felt guilty, the typical mixture of grief emotions and uncertainty about her own role in what had happened, which needed to be vented. This was followed by a preoccupation with closure, which began to shift when she attended the family's memorial service, that became a cathartic ritual in place of burial and started the process of finally coming to terms by giving up wishful thinking. She still needed some support with moving out of the joint flat that had belonged to him, and with the sorting out and letting go of his belongings, another very painful part of the bereavement process, which meant that she had accepted that he had definitely gone for good.

Moving into another flat she encountered a good friend of her late partner and struck up a relationship with him which was a comfort, but it also made her feel guilty and premature. Somewhat further on, she tentatively began to think about a future without him, and slowly it became possible to make more realistic plans.

The counsellor accompanied flexibly the various phases of the process, which divided up the nine sessions allowed by the client's employer into the 
beginning, the middle and the end of the process that at first had seemed endless. There was a break for Easter before the last session, and when the client came back, she said that she felt she had done enough counselling for the time being. It had been invaluable for her and she now knew where to go if she needed more, but she wanted to experience standing on her own feet again. In view of her age ( 29 years), this seemed sensible and emphasized the age-specific theme of 'individuation', the resilience of the young and an avoidance of regressive dependence.

There had been no time or space to go into the client's life history, as the focus was the bereavement, though past losses were mentioned and taken into account, and when the two of them met for the last counselling session, this seemed sufficient for now. It was a mutually planned and well-prepared ending and a moving experience for both. As a piece of post-traumatic debriefing the work was exemplary, as the client had shown herself up to the task in hand and as suitable for the brief treatment, yet not yet ready for more.

\section{References}

Coltart, N. (1996). Endings: The baby and the bathwater. London: Karnac Books.

Davanloo, H. (2000). Intensive short-term psychotherapy: Selected papers of Habib Davanloo. Chichester: Wiley.

Mace, C. (1995). The art and science of assessment. London: Routledge.

Malan, D. (1979). Individual therapy and the science of psychodynamics. London: Butterworth. Stern, D. (2004). The present moment in psychotherapy and everyday life. London: W. W. Norton. Wiener, J., \& Sher, M. (1998). Counselling and psychotherapy in primary health care. London: Palgrave Macmillan. 
Copyright of Psychodynamic Practice is the property of Routledge, Ltd.. The copyright in an individual article may be maintained by the author in certain cases. Content may not be copied or emailed to multiple sites or posted to a listserv without the copyright holder's express written permission. However, users may print, download, or email articles for individual use. 